\title{
Reasons to act, reasons to require, and the two-level theory of moral explanation
}

\author{
Löschke, Jörg
}

\begin{abstract}
Reasons to act, reasons to require, and the two-leveltheory of moral explanationJo"rg Lo “schke1ÓSpringer Nature B.V. 2020AbstractDeontic buck-passing aims to analyse deontic properties of acts in termsof reasons. Many authors accept deontic buck-passing, but only few have discussedhow to understand the relation between reasons and deontic properties exactly.Justin Snedegar has suggested understanding deontic properties of acts in terms ofboth reasons and reasons to require: $\mathrm{A}$ is required touiff (1) A has most reason tou, and (2) there is most reason to require A tou. This promising proposal faces twoopen questions: the question of why there can only be most reason to require A touif A has most reason tou, and the question of what role agent-relative reasons playin generating requirements. In this paper, I address these questions and argue thatthe key to answering them is to reject evaluative buck-passing and accept a value-based theory of practical reasons instead. The result is a two-level theory of moralexplanation: on the first level, practical reasons are explained in terms of appropriateresponses to value; on the second level, deontic properties of acts are explained interms of reasons: reasons to act as well as reasons to require.
\end{abstract}

DOI: https://doi.org/10.1007/s11098-020-01426-x

Posted at the Zurich Open Repository and Archive, University of Zurich

ZORA URL: https://doi.org/10.5167/uzh-188740

Journal Article

Accepted Version

Originally published at:

Löschke, Jörg (2021). Reasons to act, reasons to require, and the two-level theory of moral explanation. Philosophical Studies, 178(1):169-185.

DOI: https://doi.org/10.1007/s11098-020-01426-x 


\title{
Reasons to Act, Reasons to Require, and the Two-Level Theory of Moral Explanation
}

\author{
Jörg Löschke
}

\section{Forthcoming in: Philosophical Studies}

Buck-passing accounts seek to analyse normative phenomena in terms of reasons. The most well-known kind of buck-passing is evaluative buck-passing, according to which evaluative properties are to be analysed in terms of reasons: the property of being good 'is not a property that itself provides a reason to respond to a thing in certain ways. Rather, to be good or valuable is to have other properties that constitute such reasons.' [Scanlon 1998: 97] Evaluative buckpassing has been widely discussed, and both its advantages and problems have become clear by now. ${ }^{1}$ But the buck-passing strategy is not limited to the evaluative domain: it can be fruitfully applied to the deontic domain as well. A deontic buck-passing approach analyses deontic properties of acts, such as the property of being morally required, permitted, forbidden, or supererogatory, in terms of reasons. While many authors explicitly or implicitly assume the truth of deontic buck-passing, only few have discussed how the deontic buck-passer should formulate her view. How exactly should we understand the relation between reasons and the deontic status of acts?

Justin Snedegar [2016] has recently argued that the best way for the deontic buck-passer to proceed is to analyse requirements conjunctively, namely in terms of both reasons to act and reasons to require. This approach is very promising, but it faces at least two challenges. I will

\footnotetext{
${ }^{1}$ For an overview of strengths and weaknesses of evaluative buck-passing, see Suikkannen [2009]; Olson [2013]. Here, I will assume a metaphysical version of buck-passing, although some authors understand it as a conceptual matter. See Väyrynen [2006: 299].
} 
identify these challenges and argue that a specific version of a value-based theory of practical reasons is well-suited to address them. This indirectly supports the value-based theory of reasons that I have in mind, because it means that the theory is better suited to make sense of an important part of our moral practice than a reasons first approach. And it has an interesting upshot: it suggests that we cannot pass every buck. ${ }^{2}$ The result is a two-level theory of moral explanation: on the first level, value explains reasons; on the second level, reasons explain the deontic properties of acts.

Before I begin, let me briefly motivate deontic buck-passing. Analysing the deontic status of acts in terms of reasons is attractive for two reasons. First, it is well-equipped to make sense of important parts of our moral experience [Bedke 2011: 129]. Reasons can conflict: when an agent decides whether she ought to $\varphi$, there might be reasons that speak in favour of $\varphi$-ing and reasons that speak against it. Nevertheless, she can usually decide what she ought to do, all things considered - not every situation in which reasons conflict counts as a tragic dilemma. And we can usually figure out what we ought to do by deliberating about the reasons that speak in favour of our respective options. However, even if an agent comes to the conclusion that she ought to $\varphi$, all things considered, the reasons that speak against $\varphi$-ing retain their normative force even if there are outweighed - for example, the agent ought to $\varphi$ with a feeling of regret, or she ought to $\varphi$ and apologize afterwards. Deontic buck-passers can explain this important part of our moral experience quite easily: the overall verdict what the agent ought to do derives from the verdicts about the reasons that speak in favour of or against $\varphi$-ing, but that does not mean that the verdicts about reasons disappear once the overall verdict is formed. Even if an agent ought to $\varphi$, all things considered, the reasons against $\varphi$-ing will often remain.

\footnotetext{
${ }^{2}$ For a different argument that deontic buck-passing is more plausible than evaluative buck-passing see Dancy [2000].
} 
Second, verdicts about deontic properties typically entail reasons for action [Snedegar 2016: 156]: the claim that $\mathrm{A}$ is required to $\varphi$ entails that $\mathrm{A}$ has reason to $\varphi$. Deontic buck-passing explains this entailment relation: if reasons ground requirements, then it follows that an agent who is required to $\varphi$ also has reason to $\varphi$.

I think that these considerations support deontic buck-passing sufficiently to take it seriously as a view about the relation between reasons and the deontic status of acts. ${ }^{3}$ The question is how to understand this relation exactly. This is what I will turn to now. I will mainly focus on the relation between reasons and (moral) requirements, but I will at least briefly discuss the relation between reasons and other deontic properties at the end of the paper.

Before I proceed, two clarificatory remarks are in order. First, throughout the paper, I will be concerned with moral requirements. For the sake of brevity, however, I will often omit the qualifier and simply talk about requirements. ${ }^{4}$ It would take another paper to discuss how the results of this paper apply to legal requirements, epistemic requirements, etc, and while I hope to address these matters in future work, such a complete account would go beyond the scope of this paper. Second, I will follow most authors in that I will not discriminate between the mass noun "reason" and the count noun "reasons". Hence, I will sometimes talk about the reasons that an agent has for acting, and sometimes about what she has most reason to do. I know that this is not entirely unproblematic and that distinguishing between these two ways of speaking about reason(s) is important in many respects [Fogal 2016]. However, as far as I can see, the

\footnotetext{
${ }^{3}$ A full defence of deontic buck-passing would require a discussion of the alternative view that overall notions such as 'ought' are fundamental and reasons should be analysed in terms of such overall notions. See, for example, Broome [2013; 2015].

${ }^{4}$ In what follows, I will use the term (moral) "requirements" as synonymous with (moral) duties. My usage of the term therefore differs from John Broome's in his seminal work on normative requirements. Broome understands a normative requirement as a relation that should be distinguished from the reason relation as well as the ought relation [Broome 1999]. I agree that requirements should be distinguished from reasons and oughts, but in my view, requirements entail oughts. Broome denies this.
} 
distinction between reason (mass noun) and reason (count noun) is not crucial for the purposes of this paper.

\section{Deontic Buck-Passing: Three Views}

The first version to understand the relation between reasons and requirements is straightforward: agents are required to do what they have most reason to do. ${ }^{5}$ There is widespread agreement in the literature that an agent ought to do what she has most reason to do [Schroeder 2007; Skorupski 2010; Dorsey 2013; Wedgwood 2013; Whiting 2017], and proponents of this straightforward view thus make the further claim that what you ought to do and what you are required to do are the same thing.

It is certainly plausible that an agent ought to do what she has most reason to do. It would be strange to say that A ought to $\varphi$, but that she has more reason to $\psi$. And it also seems strange to say that A has most reason to $\varphi$, but that she nevertheless ought not to $\varphi$. However, it is less plausible that what A ought to do is identical with what she is required to do.

First, this view is implausible when it comes to permissions. Suppose that I offer you the choice between two desserts, and you strongly prefer vanilla to chocolate. It seems perfectly fine for me to tell you that you ought to choose the vanilla dessert, but you are certainly not required to do so. You may choose whatever dessert you like. Or consider what Joseph Raz calls the 'basic belief' [Raz 1999: 100]: in a typical choice situation, we face several options that we are permitted to perform, such as reading a newspaper, calling our parents, volunteering for charity, going for a run, etc. The straightforward view implies that the basic belief is only true if the reasons that support these options are of the exact same weight. But it would certainly be a great

\footnotetext{
${ }^{5}$ This seems to be the view of Philip Pettit [2015: 205].
} 
coincidence if every situation in which $\mathrm{A}$ is permitted to choose between different options would be such that the reasons for these options balance out exactly.

Another problem with the straightforward view is that it is notoriously difficult to accommodate supererogation within this approach. A supererogatory act goes beyond the call of duty: it is morally better than the required alternative. Since supererogatory acts are morally best, they are also supported at least by the strongest moral reasons. Hence, they should be required according to the straightforward view. But they are not required - they are supererogatory. The straightforward view thus cannot make sense of supererogation. ${ }^{6}$

Finally, the straightforward view has problems to explain the thought that moral requirements have a certain directedness. Moral duties are owed to specific people (Anne owes it to Bert to respect Bert's bodily integrity), or to the moral community as such (Chris owes it to the moral community not to dispose of his radioactive waste in the Great Barrier Reef). ${ }^{7}$ A convincing theory of moral requirements must explain this directness of moral duties, and it is not obvious that the straightforward view can do this, because it is not obvious how to get from reasons to directed duties. Reasons can be directed, but their directedness differs from the directedness of moral requirements. If A owes B to $\varphi$, then A wrongs B if she does not $\varphi$. B can demand that A $\varphi s$, A owes B an apology if she does not $\varphi$, etc. By contrast, it is difficult to see how B can demand that $\mathrm{A}$ acts on her reason to $\varphi$ if A does not already have a duty to $\varphi$. Directed reasons are not reasons that others can demand acting on, but reasons to do things for the sake of others: A's reason to $\varphi$ is a directed reason to B if $\varphi$-ing is done for the sake of B. For example, A's

\footnotetext{
${ }^{6}$ For a discussion of this 'puzzle' of supererogation, see, for example, Horgan/Timmons [2010]. Brian McElwee [2011] also rejects the view that we are required to do what we have most reason to do on grounds that this would be overdemanding.

${ }^{7}$ Are all moral duties directed in this way? I tend to think that they are, but this is a controversial claim, and I do not have the space to defend it here. However, even if not all moral duties are directed, many of them are, and the straightforward view has problems with this important subset of moral requirements.
} 
reason to help B move house is a directed reason to B because helping B move house is done for the sake of B. But even if A has such a directed reason to B, and even if this reason outweighs all other reasons, it is not obvious that A has a directed duty to B. Even if A can help B move house and has no stronger reason to do something else, it does not follow that B can demand that A helps him move house. There is no obvious way how to get from directed reasons to directed duties, and this is a problem for the straightforward view.

An interesting alternative to the straightforward view comes from Matt Bedke. Bedke proposes to 'distinguish reasons that favor A's Фing from reasons that favor some response to A's Фing, and analyze requirements in terms of the latter.' [Bedke 2011: 136] According to Bedke, 'A is required to $\Phi$ iff there is most reason $[\ldots]$ to require A to $\Phi$. A is permitted to $\Phi$ iff there is most reason to permit A to $\Phi . '$ [Bedke 2011: 137] And so on. This view has several advantages. It explains why you are not required to choose the vanilla dessert instead of the chocolate dessert, since there is not most reason to require you to do so (say, because the matter is too trivial). It also seems to have the theoretical resources to accommodate supererogation: there might be good reason not to require the agent to perform a supererogatory act even if the act is supported by very weighty (and possibly the strongest) moral reasons (for example, because the cost to the agent is too great). And the view also gives a sound explanation for the directedness of moral duties: if A's duty to $\varphi$ depends on others having most reason to require A to $\varphi$, then the interpersonal character of moral demands is built into the concept of a moral requirement from the very beginning.

However, the account also faces a serious problem. Bedke emphasizes that 'reasons for requiring A's Фing are conceptually independent of A's reasons for Фing.' [Bedke 2011: 138] Of course, a reason to $\varphi$ will often also count as a reason to require to $\varphi$ [Bedke 2011: 138]: the fact that $\varphi$-ing will cause unnecessary pain to a sentient being is both a reason for A not to $\varphi$ and a reason for others to require A not to $\varphi$. But whether A's reason to $\varphi$ is also a reason to 
require $\mathrm{A}$ to $\varphi$ is a contingent matter. And this leaves open the possibility that $\mathrm{A}$ is required to $\varphi$ (because there is most reason to require him to $\varphi$ ) even if A has no reason to $\varphi$. This is certainly an awkward implication. If you blame someone for not $\varphi$-ing and that person can convincingly show that she had no reason to $\varphi$ in the first place, then this seems to be a pretty good excuse for her not to $\varphi .^{8}$

A similar worry with Bedke's account is that it cannot explain certain entailments that are intuitively very plausible [Snedegar 2016]. It is very plausible to assume that requirements entail oughts, but not vice versa: if you are required to $\varphi$, then it is also true that you ought to $\varphi$, but as the discussion of the straightforward view illustrated, it is not generally true that if you have most reason (and hence ought) to $\varphi$, then it is also the case that you are required to $\varphi$. Since reasons to $\varphi$ and reasons to require to $\varphi$ are conceptually independent on Bedke's account, it is difficult to explain this entailment relation. It seems to be a great coincidence that you always ought to do what you are required to do, but not vice versa.

A promising refinement of Bedke's account has been put forward by Justin Snedegar. Snedegar tentatively suggests a conjunctive view of requirements according to which '[...] $s$ ought to $A$ iff $s$ has most reason to $A$ ' and that ' $[\ldots] s$ is required to $A$ iff (i) $s$ has most reason to $A$, and (ii) there is most reason to require $s$ to $A .^{\prime}$ [Snedegar 2016: 176]. The immediate question is who has the standing to require an agent to $\varphi$, and Snedegar plausibly follows Bedke in arguing that every member of the moral community has the standing to require $\mathrm{A}$ to $\varphi$ if there is most reason to require A to $\varphi$ [Bedke 2011: 144; Snedegar 2016: 165]. This is insofar convincing as it introduces the plausible idea that all members of the moral community can hold each other accountable for violating moral requirements ${ }^{9}$ and it therefore expresses a kind of moral

\footnotetext{
${ }^{8}$ Other authors who argue that it is incoherent to blame someone for not $\varphi$-ing if they had no reason to $\varphi$ include Gibbard [1990]; Williams [1995]; Darwall [2010]. See also Snedegar [2016: 177].

${ }^{9}$ I will return to this point below, as it is slightly more complicated.
} 
universalism that many find attractive. ${ }^{10}$ Snedegar's view keeps all advantages of Bedke's account, but it blocks the possibility that an agent is required to do something that she has no reason to do (resp. something that she ought not to do). This framework that analyses the deontic status of acts in terms of both Reasons and Reasons to Require (or RRR in short) is therefore a very promising account of deontic buck-passing. ${ }^{11}$

As it stands, proponents of RRR need to address two open questions. First, they need to explain why there can only be most reason to require somebody to do something that the person has most reason to do. As Snedegar [2016: 176] himself points out, this might appear ad hoc: condition (i) seems to be introduced simply to yield the right results. But the problem runs deeper: the account allows for the 'odd result' [Snedegar 2016: 177] that there is most reason to require a person to $\varphi$ but that the person is nevertheless not required to $\varphi$ because she does not have most reason to $\varphi$. Thus, the account leaves open the possibility that there is most reason to require somebody to do something that she ought not to do, and it also leaves open the possibility that there is most reason to require the agent to do something that (everyone knows) she is not required to do [Snedegar 2016: 177]. Second, proponents of RRR need to address the role of agent-relative reasons. It is plausible to assume that agent-relative reasons contribute to moral requirements, and the question is how RRR accounts for this. I will address these questions in turn.

\footnotetext{
${ }^{10}$ Some readers might find talking of reasons to require odd since nobody does the actual requiring. However, the view does not presuppose agents who actually do the requiring. Reasons to require can also be understood along the lines of moral principles that parties agree upon in contractualist accounts of morality. Just as, say, the Rawlsian principles of justice hold even if nobody actually agreed upon them, there can be reasons to require even if nobody actually does the requiring.

${ }^{11}$ I cannot provide a full defense of RRR here. Rather, I will assume that it is a promising approach and discuss how to best formulate the view. For a more detailed defense of RRR, see Snedegar [2016].
} 


\section{Reasons to Act and Reasons to Require}

The key to answering both open questions is to give up reasons fundamentalism. Reasons fundamentalists understand reasons as the basic normative entities and hold that no further explanations for facts about reasons can be given. Snedegar formulates the first open question as a challenge to reasons fundamentalism, and rightfully so: given that reasons fundamentalists understand facts about reasons as primitive normative truths, it is difficult for the reason fundamentalist to explain conceptual connections between reasons to $\varphi$ and reasons to require to $\varphi$. A value-based theory of reasons does not face this problem: according to such a theory, it is possible to explain facts about reasons, including conceptual connections between different kinds of reasons. And this also helps to answer the second open question: if it is possible to explain conceptual connections between reasons to $\varphi$ and reasons to require to $\varphi$, then it might also be possible to explain conceptual connections between agent-relative reasons to $\varphi$ and reasons to require to $\varphi$. In what follows, I will sketch a theory that explains both of these open questions.

The value-based theory of practical reasons that I have in mind draws from Thomas Hurka's [2001] recursive account of value. ${ }^{12}$ The idea is that practical reasons are value-based in the sense that agents have practical reasons to respond appropriately to value: A has a reason to $\varphi$ if and because $\varphi$-ing is an appropriate response to a valuable entity. ${ }^{13}$ Furthermore, appropriate

\footnotetext{
${ }^{12}$ I do not claim that Hurka would accept everything that I am about to say. However, the view developed here has been inspired by his work.

${ }^{13}$ Note that, even though this formulation includes the notion of appropriateness, it is a value-based account of practical reasons, not a fittingness-first approach as defended by Yetter Chappell [2012] or McHugh/Way

[2016]. The idea is that the appropriateness of a response to a valuable entity is determined by the valuable entity and needs to be explained by the value of the entity. It is not normative bedrock. In other words: according to my view, the value of the entity determines the appropriateness of the response, whereas fittingness-first approaches hold that the appropriateness of the response determines the value of the object. I thank an anonymous referee for pressing me on this point.
} 
responses to value are intrinsically good: a world in which agents respond appropriately to value is better than a world in which they fail to do so, even if their appropriate value responses have no further beneficial effects [Hurka 2001]. Both assumptions are independently plausible, and together they explain the conceptual connections between reasons to $\varphi$ and reasons to require to $\varphi$.

On this view, we can explain reasons to $\varphi$ directly in terms of appropriate responses to valuable entities. These reasons speak for and against certain courses of action and the act that is supported by the strongest reasons is the act that the agent ought to perform. Of course, proponents of the view must explain what makes it the case that one reason is stronger than another; I cannot discuss this question here. I will simply assume that this can be done, and that proponents of this appropriate response view of practical reasons can therefore explain how reasons to $\varphi$ arise and how they generate oughts.

What about reasons to require? Requiring is an activity, and this means that reasons to require are also practical reasons. It is tempting to understand reasons to require analogously to reasons to $\varphi$, that is: in terms of appropriate responses to the same valuable entities. For example, one might think that it is an appropriate response to the value of a person not to harm her, and that A therefore has a reason not to harm that person. Similarly, one might think that it is an appropriate response to the value of that person to require A not to harm her, and that there is therefore reason to require A not to harm her. This account of reasons to require appears plausible at first, but I do not think that it ultimately succeeds. Its main problem is that reasons to $\varphi$ and reasons to require to $\varphi$ remain conceptually independent on this picture. And this means that, even if they stem from the same source, it is possible that $\varphi$-ing is an appropriate response to a valuable entity, whereas requiring an agent to $\varphi$ is not an appropriate response to that very same entity. And it is also possible that requiring someone to $\varphi$ is an appropriate response to a 
valuable entity, although $\varphi$-ing is not an appropriate response to that valuable entity. ${ }^{14}$ Hence, the account cannot tell us why there can only be most reason to require someone to $\varphi$ if that person has most reason to $\varphi .{ }^{15}$ There is no guarantee that reasons to $\varphi$ and reasons to require to $\varphi$ co-exist in the way that is needed to get RRR off the ground.

Of course, I do not deny that reasons to $\varphi$ and reasons to require to $\varphi$ can both be appropriate responses to the same valuable entity. The example of harming a person is a case in point. My point is that reasons to $\varphi$ and reasons to require to $\varphi$ can come apart on this view and only contingently align in some cases. We should therefore search for an alternative account of reasons to require that maintains the plausible idea that they ultimately stem from the same values as the reasons to act and that also explains conceptual connections between reasons to $\varphi$ and reasons to require to $\varphi$.

Luckily, such an account is available. It builds on the aforementioned idea that appropriate responses to value are intrinsically good and operates with different levels of value response. Instead of understanding reasons to require in terms of appropriate responses to the valuable entities that ground reasons to $\varphi$, reasons to require should be understood in terms of appropriate responses to the value of $\varphi$-ing. They should therefore be understood in terms of appropriate responses to appropriate (or inappropriate) value responses: there is a reason to require $\mathrm{A}$ to $\varphi$ if and because requiring A to $\varphi$ is an appropriate response to the value (or disvalue) of A's $\varphi$ -

\footnotetext{
${ }^{14}$ For example, it might be that it is an appropriate response to the value of a person to befriend her, but it is not an appropriate response to the value of a person to require others to befriend her. It is more difficult to come up with an example where it is an appropriate response to some entity $E$ to require a person to $\varphi$, whereas it is not an appropriate response to $\mathrm{E}$ to $\varphi$. The important point, however, is that there is simply no guarantee that, whenever it is an appropriate response to $\mathrm{E}$ to require an agent to $\varphi$, it is also an appropriate response to $\mathrm{E}$ to $\varphi$. Even if it is difficult to come up with a counterexample, this does not show that there are the necessary conceptual connections between reasons to $\varphi$ and reasons to require to $\varphi$ for RRR to work.

15 The same problem emerges for an alternative view according to which reasons to require to $\varphi$ are appropriate responses to the value of requiring an agent to $\varphi$.
} 
ing (or not $\varphi$-ing) qua appropriate value response. For example, harming a person (call her B) is an inappropriate response to B's value, and A therefore has a reason not to harm B. According to the recursive account, this means that harming B is intrinsically bad qua inappropriate value response. As an intrinsically bad entity, the harming of B also calls for an appropriate response and therefore generates further reasons for action. And one way to respond appropriately to the intrinsic disvalue of harming B is to require A not to harm B. On this picture, reasons to require can be explained in terms of higher-order value responses: requiring someone to $\varphi$ is an appropriate response to the value of a first-order value response and hence a response to a response.

This view has several advantages over the view that reasons to require stem from the very same valuable entities that generate reasons to $\varphi$. First, it clearly explains the conceptual connections between reasons to $\varphi$ and reasons to require to $\varphi$ : there cannot be a reason to require somebody to $\varphi$ if that person has no reason to $\varphi$, since reasons to require depend on the value of the $\varphi$-ing and therefore on there being reasons to $\varphi$. Second, it is intuitively plausible that the reasons to require an agent to $\varphi$ must have something to do with the value of the $\varphi$-ing and not merely with the value of the $\varphi$-ing's objective. After all, there can be reason to require somebody not to $\varphi$, even if $\varphi$-ing serves a valuable goal (for example, because $\varphi$-ing involves the killing of an innocent person). Third, the view is in line with an intuitively plausible view about the relative strength of reasons to $\varphi$ and reasons to require somebody to $\varphi$. In his formulation of the recursive account, Hurka convincingly argues that, while appropriate responses to value are intrinsically good, they are less valuable than the objects of their response [Hurka 2001]. On the plausible assumption that the strength of a value-based reason corresponds in some way to the value of the reason-generating entity, this suggests that a reason to $\varphi$ is typically stronger than the corresponding reason to require someone to $\varphi: \varphi$-ing is the object of the response and it is therefore more valuable than the response (the requiring). A reason to $\varphi$ should therefore 
be stronger than a reason to require someone to $\varphi$. And this seems to be the right result. Suppose that you can either prevent Alfred from harming Beth or prevent Chris from failing to require Alfred not to harm Beth. It seems clear that in such a situation your reason to prevent Alfred from harming Beth is stronger than your reason to prevent Chris from failing to require Alfred not to harm Beth. This suggests that reasons to $\varphi$ are typically stronger than reasons to require, and the appropriate response view of practical reasons can explain this independently plausible fact.

Hence, the recursive account of value explains the conceptual connections between reasons to $\varphi$ and reasons to require. However, this does not yet explain why there can only be most reason to require a person to do something if she has most reason to do it. As far as I can see, two explanations are possible here. The first is to assume a direct link between reasons to $\varphi$, reasons to require to $\varphi$, and their respective strengths: whenever an agent has a reason to $\varphi$, there is a corresponding reason to require the agent to $\varphi$, and the stronger the reason to $\varphi$, the stronger the corresponding reason to require. It is therefore conceptually impossible that a reason to $\varphi$ is too weak to make it the case that an agent ought to $\varphi$ while the corresponding reason to require to $\varphi$ is strong enough to make it the case that there is most reason to require the agent to $\varphi$. Reasons to require can only be sufficiently strong to yield requirements if the corresponding reasons to $\varphi$ also yield oughts.

The problem with this view is that such a link between the strength of a reason to $\varphi$ and the strength of a reason to require to $\varphi$ would make it not only impossible that there is most reason to require to $\varphi$ without there also being most reason to $\varphi$, but also that there is most reason to $\varphi$ without there also being most reason to require to $\varphi$. After all, the strength of a reason to $\varphi$ translates into the strength of the corresponding reason to require to $\varphi$, and most reason to $\varphi$ therefore translates into most reason to require to $\varphi$. Hence, it could never be the case that an agent ought to $\varphi$ without being required to $\varphi$. The suggested view thus cannot explain cases of 
supererogation or cases of prudential reasons that yield no requirements - but such cases motivate the distinction between reasons to $\varphi$ and reasons to require to $\varphi$ in the first place!

A second and more promising view operates with the distinction between favourers and enablers that has been introduced by Jonathan Dancy [2004]. Dancy's idea is that different considerations play different roles when determining what an agent ought to do. Favourers are considerations that speak in favour of $\varphi$-ing: they are the actual reasons. Enablers, by contrast, are not reasons to $\varphi$, but they are nevertheless important in determining what an agent ought to do: they enable other considerations to be favourers and hence to constitute reasons to $\varphi$. Take the example of a freely given promise [Dancy 2004: 38]. The fact that I promised to do something is a reason for me to do that thing. By contrast, the fact that my promise was not given under duress 'is not a second reason for doing the action [...]. What is true here is that if my promise had been given under duress, I would have had no reason to keep it.' [Dancy 2004: 39] The fact that my promise to $\varphi$ was not given under duress is by itself not reason to $\varphi$, but it enables the fact that I have promised to $\varphi$ to constitute a reason for me to $\varphi$.

I suggest understanding the fact that an agent has most reason to $\varphi$ as an enabler. Just as the fact that my promise was not given under duress enables the fact that I promised to $\varphi$ to constitute a reason for $\varphi$-ing does the fact that $\mathrm{A}$ has most reason to $\varphi$ enable other considerations (such as the value of A's $\varphi$-ing) to constitute a reason to require $\mathrm{A}$ to $\varphi .{ }^{16}$ This explains why it is impossible that a person is required to do something that she does not have most reason to do,

\footnotetext{
${ }^{16}$ An anonymous referee has pointed out to me that this appeal to enablers is available to everyone interested in the connection between reasons to $\varphi$ and reasons to require to $\varphi$ and does not require the recursive account. This is true, and what I am about to say should therefore be interesting for proponents of alternative approaches as well. However, for reasons given above, I think that we should also accept the recursive theory. Even if an alternative view can explain conceptual connections between reasons to $\varphi$ and reasons to require to $\varphi$ by appealing to enablers, it cannot account for the intuitively plausible idea that reasons to require must have something to do with the value of the $\varphi$-ing, and it cannot account for the plausible view about the relative strengths of the reasons to $\varphi$ and the reasons to require to $\varphi$.
} 
because if she does not have most reason to $\varphi$, then there is no reason (let alone most reason) to require her to $\varphi$. Nevertheless, what an agent ought to do is not identical with what she is required to do: the fact that an agent has most reason to $\varphi$ does not entail that there is most reason to require the agent to $\varphi$. It only entails that there are reasons to require the agent to $\varphi$, but these reasons can be outweighed by reasons not to require the agent to $\varphi$. Hence, there can be oughts without requirements, but there cannot be requirements without oughts.

This leads to an obvious question: why is the fact that A has most reason to $\varphi$ an enabler for other considerations to constitute reasons to require A to $\varphi$ ? To answer this question, it is helpful to reflect on Dancy's example of promise-keeping again. Why is the fact that my promise was not given under duress an enabler for the fact that I promised to do something to count as a reason to do that thing? A plausible explanation is that it is part of the social practice of promising that promises must be freely given to be binding because a promise that is given under duress does not fulfil its role: it does not express a free binding of the will. Similar considerations apply to the case of oughts and requirements.

An important feature of moral requirements is their special action-guiding character: they tell us what we must do, morally speaking. ${ }^{17}$ By telling us what we must do, they express overall verdicts regarding our actions, and in this regard they differ from other action-guiding verdicts such as claims about pro tanto reasons, which are merely claims about what speaks in favour of certain courses of action. The important point is that claims about what an agent has most reason to do also express overall action-guiding overall verdicts. They might not be claims about what an agent must do, but rather claims about what would be best to do, but they are overall action-guiding verdicts, nevertheless. And this means that, if it were not the case that an

\footnotetext{
${ }^{17}$ I rely here on an intuitive notion of the action-guidance of moral duties. As an anonymous referee has pointed out to me, this might not be entirely unproblematic, because it is often unclear how to determine when some reason, requirement, or ought is action-guiding in the relevant sense. I cannot address the question of a proper understanding of the action-guidance of moral duties here, but I hope to do so in future research.
} 
agent ought to do what she is required to do (that is: if she did not have most reason to do what she is required to do), then moral requirements could not fulfil their action-guiding role. After all, if an agent would be required to do one thing, but had most reason to do something else, then she would face two overall action-guiding verdicts about what to do, and it would not be clear which of these overall verdicts she should follow. Just as a promise must be freely given to fulfil its normative role, a moral requirement must be action-guiding to fulfil its normative role. This explains why the fact that an agent has most reason to $\varphi$ is a precondition - or, in other words, an enabler - for there to be most reason to require the agent to $\varphi$.

To avoid misunderstanding: I do not claim that it is problematic per se when two action-guiding verdicts conflict. It is problematic when two overall action-guiding verdicts conflict. Pro tanto reasons are action-guiding in a sense, and they often conflict. But this does not cause any conceptual problems because when two pro tanto reasons conflict, one reason usually outweighs the other, and the agent can form a single overall verdict about what she ought to do. But when two overall verdicts conflict, the agent is left without any guidance as to which verdict to follow. This is also the reason why, even though what an agent ought to do is not necessarily what she is required to do, claims about what an agent ought to do could not fulfil their actionguiding role if they would actually conflict with what the agent is required to do. Hence, even if an agent is not necessarily required to do what she ought to do (as in some cases of supererogation), it cannot be the case that the agent ought to do one thing, but is required to do something else. ${ }^{18}$

\footnotetext{
${ }^{18}$ An anonymous referee has objected that the argument from action-guidance only supports that the agent having most reason to $\varphi$ is an enabler for the normative status of the agent being required to $\varphi$ to hold, but not necessarily that there would be any troubling conflict between an agent having most reason to $\varphi$ and some other agent having most reason to $\psi$, even if $\psi$-ing consists in requiring the first agent to do something other than $\varphi$ ing. I do not think that this is a problem for the account suggested here. Either the other agent's $\psi$-ing has the normative upshot that the first agent is required to $\psi$, or it doesn't. If it does, then the argument does show that
} 
To illustrate my proposal further, it might be helpful to compare it with a proposal that Snedegar briefly discusses in his essay, namely the proposal that it is simply a conceptual truth that there can only be most reason to require an agent to $\varphi$ if the agent has most reason to $\varphi$ [Snedegar 2016: $176-178] .{ }^{19}$ This proposal might appear similar to the appeal to enablers: both proposals hold that reasons to require depend on the agent's reasons to $\varphi$, and both proposals explain connections between reasons to $\varphi$ and reasons to require to $\varphi$. However, there are important differences between the conceptual proposal and the appeal to enablers. The appeal to enablers is not a conceptual claim, but a metaphysical claim. It does not specify under what conditions it is coherent to require someone to $\varphi$, but what makes it the case that there is reason to require someone to $\varphi \cdot{ }^{20}$ And what makes it the case that there is reason to require an agent to $\varphi$ is that it is appropriate to do so under certain circumstances. More specifically, it is only appropriate to require her if she has most reason to $\varphi$, due to the action-guiding role of moral requirements: when an agent needs practical guidance on what to do, it would be inappropriate to present her with two different and contradictory overall verdicts about what to do.

Another difference between the appeal to enablers and the conceptual proposal is this. It is difficult to explain why the conceptual claim holds. Snedegar considers the argument that it would be incoherent to accept that a person had more reason to not- $\varphi$ than she had reason to $\varphi$

\footnotetext{
the agent having most reason to $\varphi$ is an enabler for the other agent to $\psi$ (where $\psi$-ing means requiring the first agent to do something else than $\varphi$-ing), since the other agent's $\psi$-ing would lead to conflicting overall judgements. If the other agent's $\psi$-ing does not lead to the first agent being required to $\psi$, then there might be no troubling conflict between the first agent having most reason to $\varphi$ and the second agent having most reason to $\psi$ - this is true. But this would not be problematic for the view put forward here, since it would support the claim that reasons to require to $\psi$ are not sufficient for the normative status of being required to $\psi$ to hold.

${ }^{19}$ I thank an anonymous referee for encouraging me to discuss the difference between my proposal and the one that Snedegar discusses.

${ }^{20}$ I take this to be an advantage of the view proposed here, because, as Snedegar himself points out, the conceptual claim might be difficult to defend.
} 
and nevertheless continue to blame her for not- $\varphi$, and he rightfully points out that this is not an explanation for why the conceptual claim holds, but rather a restatement of the claim [Snedegar 2016: 178]. By contrast, the appeal to enablers gives an independent explanation for why there can only be most reason to require someone to $\varphi$ if she has most reason to $\varphi$, an explanation that relies on ideas of appropriateness and the action-guiding role of moral requirements. It therefore has more explanatory depth than the conceptual proposal. ${ }^{21}$

To sum up, the recursive account, together with the idea of the action-guidingness of moral requirements, can explain why there can only be most reason to require someone to $\varphi$ if that person has most reason to $\varphi$. This answers the first open question regarding RRR.

The remaining question is the question about the role of agent-relative reasons. I have mentioned above that every member of the moral community (including the agent herself) has the standing to require $\mathrm{A}$ to $\varphi$ if there is most reason to require $\mathrm{A}$ to $\varphi$ [Bedke 2011: 144; Snedegar 2016: 165]. And this leads to a worry. If all members of the moral community have the standing to require $\mathrm{A}$ to $\varphi$, if moral requirements are grounded in there being most reason to require an agent to $\varphi$, and if reasons to require are reasons that all members of the moral community share, then all reasons to require seem to be agent-neutral reasons. Agent-relative

\footnotetext{
${ }^{21}$ This leads to the question how to cash out the notion of appropriateness. The notion of appropriateness denotes a relation between a valuable entity and an action, and this relation holds by providing reasons for the action. However, the notion of appropriateness itself is not to be cashed out in terms of reasons. Rather than saying that $\varphi$-ing is appropriate if and because there is reason to $\varphi$, the idea is that there is reason to $\varphi$ if and because $\varphi$-ing would be appropriate. The appropriateness of the requiring therefore does not depend on there being reasons to require, otherwise my proposal would not be very illuminating. But neither is appropriateness a primitive notion: it is possible to explain the appropriateness of a response with reference to the valuable entity. In this case, the value in question is the agent's $\varphi$-ing; and since $\varphi$-ing is an action, and actions are done for reasons, agents must be capable of acting on their reasons, and verdicts about reasons must thus be action-guiding. And again, if the agent would be required to $\varphi$, but ought to $\psi$, then this action-guidance would be lost. In this sense, it would be inappropriate to require somebody to do something that she ought not to do. I thank an anonymous referee for pressing me on this point.
} 
reasons therefore do not contribute to the requirements of agents, and this is an implausible result.

\section{Moral Requirements and Agent-Relative Reasons}

Matt Bedke who, as we saw, understands requirements merely in terms of reasons to require claims that all reasons to require are agent-neutral [Bedke 2011: 144]. This is implausible: agent-relative reasons include relationship-dependent reasons and deontological restrictions [Nagel 1986: 165], and these reasons certainly contribute to what an agent is morally required to do. But if requirements are grounded in reasons to require, and if all reasons to require are agent-neutral reasons, then it follows that agent-relative reasons do not contribute to the requirements of persons. They might contribute to what an agent ought to do, but they do not contribute to what she is required to do. RRR fares better in this regard: insofar as agent-relative reasons contribute to what an agent ought to do, and insofar as what an agent ought to do is relevant for what she is required to do, the framework does assign agent-relative reasons a role in generating moral requirements. But this is not fully satisfactory either. It restricts the normative role of agent-relative reasons to their contribution to what an agent ought to do: once it is settled what she ought to do, agent-relative reasons play no further role. But agent-relative reasons seem to be in the set of the reasons to require also. Take deontological restrictions: the normative role of these reasons is not exhausted by their contribution to what an agent ought to do. They play an additional role in what the agent is required to do. A convincing version of RRR should therefore illustrate that agent-relative reasons are in the set of reasons to $\varphi$ as well as the set of reasons to require to $\varphi$, and I think it is an advantage of the view that I sketched here that it can do so.

It is uncontroversial that agent-relative reasons as well as agent-neutral reasons are part of the set of reasons that are weighed against each other to determine what an agent has most reason 
to do, all things considered. The interesting question is in what way agent-relative reasons are part of the relevant set of reasons to require. Two possibilities need to be examined here: A's agent-relative reasons could ground reasons to require A to $\varphi$, or there could be agent-relative reasons to require A to $\varphi$. In the first case, the agent-relative reasons of $A$ contribute to A's requirements. In the second case, the agent-relative reasons of the requiring person contribute to A's requirements.

Can A's agent-relative reasons to $\varphi$ constitute reasons for all members of the moral community to require A to $\varphi$ ? The answer is arguably "yes", and the framework developed in this paper explains why. Take deontological restrictions. Suppose that respecting a deontological restriction is an appropriate response to the value of the potential victim. If A acts on his agentrelative reason and refrains from harming $\mathrm{B}$, then $\mathrm{A}$ responds appropriately to value. This response is intrinsically good and therefore generates further reasons - reasons to respond appropriately to the value of A's appropriate value response, including reasons to require A to respect the deontological restriction (if A also has most reason to respect the restriction, which I will assume). And similar considerations apply to relationship-dependent reasons. Suppose that a father who cares for his child thereby responds appropriately to the value of his child, or to the value of the father-child-relationship. ${ }^{22}$ This means that he has a reason to care for his child, and that it is intrinsically good if he does. And this in turn means that his caring for his child generates reasons for the members of the moral community to respond appropriately to the value of the father's appropriate value response, including reasons to require the father to care for his child. A's agent-relative reasons can thus contribute to her requirements not only by contributing what $\mathrm{A}$ ought to do, but also to what $\mathrm{A}$ is required to do in that they can ground reasons to require A to act on her agent-relative reasons.

\footnotetext{
${ }^{22}$ Philosophers disagree whether relationship-dependent reasons are grounded in the value of the relationship or the value of the other person. See, among others, Keller [2013] and Lord [2016].
} 
The second possibility is more complicated. Can there be agent-relative reasons to require in the sense that they are agent-relative reasons of the requiring agent, not of the required agent? This might seem problematic because it might lead to indexical requirements: it leaves open the possibility that A has most reason to require B to $\varphi$ (because A's agent-relative reasons to require speak in favour of requiring B to $\varphi$ ), whereas $\mathrm{C}$ has most reason to require B to $\psi$ (because C's agent-relative reasons to require speak in favour of requiring B to $\psi$ ). Moral requirements would then be relative to the requiring agent: relative to $\mathrm{A}, \mathrm{B}$ is required to $\varphi$, but relative to $\mathrm{C}, \mathrm{B}$ is required to $\psi$. This would mean, for example, that Eric is required ${ }_{\text {Fred }}$ not to lie (because Fred has most reason to require Eric not to lie), whereas Eric is required Liza $_{\text {to }}$ lie (because Liza has most reason to require Eric to lie). Requirements would then again cease to be action-guiding.

However, agent-relative reasons to require do not necessarily lead to such indexical requirements. Consider the case of relationship-dependent reasons. It is often up to the participants of a relationship to determine its exact normative contours. For example, friendships usually involve various duties of assistance, but there can also be what Simon Keller [2013: 51] calls 'undemanding friendships', namely friendships without such special obligations. Friendships therefore involve agent-relative reasons to require: friends have reasons to require each other to $\varphi$ that other people do not have.

Now, one might think that friends can determine the normative contours of their relationship, but as soon as they agree that their friendship involves a duty to $\varphi$, everybody has reason to require them to $\varphi$. This would mean that all reasons to require are agent-neutral after all. But I do not think that this possible objection shows that there are no agent-relative reasons to require. Requirements are conceptually linked to the appropriateness of certain reactive attitudes: when A violates a moral requirement, then it is appropriate to blame him, and thus there is reason to blame him. And reasons to blame are often agent-relative in the sense that not every member 
of the moral community has the same reason to blame every other member of the moral community who has acted wrongly. Suppose that A forgets to buy her friend B a birthday present, even though A and B have tacitly agreed that their friendship includes a duty to buy each other birthday presents. In this case, B has a reason to blame A. But it would be inappropriate if $\mathrm{C}$, a stranger who has somehow learned that $\mathrm{A}$ forgot to buy a birthday present for B, would blame A in the very same way as B does. C does not have the same reason to blame A as B does - he might have no reason at all to blame A.

Agent-relative reasons to require can be explained along these lines. If $\mathrm{A}$ is required to $\varphi$, then A is required to do so, period. His requirement is not indexed to any requiring agent. But in some cases, certain individuals can make it the case that $\mathrm{A}$ is required to $\varphi$, whereas others cannot make it the case that $\mathrm{A}$ is required to $\varphi$. Furthermore, certain individuals can have agentrelative reasons to hold $\mathrm{A}$ responsible and blame her for violating a requirement, reasons that are not shared by others, even if those others can form the judgement that A has acted wrongly. Agent-relative reasons thus play several roles according to RRR. They contribute to what A has most reason to do; A's agent-relative reasons can generate agent-neutral reasons to require A to $\varphi$; and some reasons to require can be agent-relative. ${ }^{23}$

\section{Moral Permissions and Supererogation}

\footnotetext{
${ }^{23}$ More work needs to be done here. For example, third parties have a greater standing to blame an agent who has violated a deontological restriction than to blame an agent who has failed to fulfil an associative duty. I do not have the space to provide a full explanation of this difference here, but I am optimistic that this can be done: presumably the explanation will refer to the fact that deontological restrictions structure the relations between all members of the moral community, whereas relationship-dependent reasons do not. A's violation of a deontological restriction therefore affects every member of the moral community, and all members of the moral community have a reason to hold A accountable.
} 
In closing, I would like to indicate how the proposed account can be extended to other kinds of deontic status, such as being permitted or supererogatory. I cannot give a full account of these other kinds of deontic status here, but since I have claimed that the straightforward version of deontic buck-passing cannot make sense of them, some remarks are in order.

Take permissions first. Note first that A does not need to have most reason to $\varphi$ in order to be permitted to $\varphi$. Agents are (morally) permitted to perform acts that are not supported by their strongest reasons - it can be morally permissible to act foolishly. To explain permissions, we thus need to focus solely on reasons to require. One possibility is that A is permitted to $\varphi$ iff there is most reason to permit $\mathrm{A}$ to $\varphi$, but this view faces the problem that required acts are also permitted, and that requiring is a different activity than permitting. The proposal might thus not explain why required acts are also permitted. Proponents of RRR can respond that every act of requiring is also an act of permitting, but not the other way round; or they can claim that $\mathrm{A}$ is permitted to $\varphi$ iff it is not the case that there is most reason to require A not to $\varphi$. In any case, RRR can account for permissions.

Explaining supererogation on the basis of RRR is more difficult. One might think that A's $\varphi$ ing is supererogatory iff (1) A has most reason to $\varphi,(2)$ there is not most reason to require A to $\varphi$, and (3) A $\varphi s$ nevertheless. This explains many cases of supererogation, but it cannot be the whole story. Suppose that A has most reason to perform a prudential act. In this case, there is not most reason to require her to do that act (agents are morally permitted to do imprudent things), but we would not say that A acts supererogatorily when she does the prudent thing. An alternative explanation is that an act is supererogatory iff (1) A does not have most reason to $\varphi$ and (2) there is not most reason to require A to $\varphi$, but this would make imprudent acts turn out to be supererogatory. And we cannot explain supererogatory acts solely in terms of reasons to require - after all, supererogatory acts are not required. There cannot be most reason to require the agent to do the supererogatory act. 
Proponents of RRR have several options to deal with supererogatory acts. One possibility is to deny that supererogation exists, but this move has considerable cost, given that common-sense morality clearly accepts supererogatory acts. Another possibility is to argue that supererogatory acts are actually required, but that the agent is permitted not to perform them. This strategy is problematic because it implies that there is most reason to require A to $\varphi$ and, at the same time, most reason to permit A not to $\varphi$. This is certainly difficult to make sense of. A more promising strategy is to introduce another class of reasons to respond to the agent's act. An agent who supererogates is worthy of praise for her saintly or heroic behaviour. Supererogatory acts might therefore be such that (1) A has most reason to $\varphi,(1)$ it is not the case that there is most reason to require A to $\varphi$, and (1) there is most reason to praise A for $\varphi$-ing. This is admittedly very tentative and needs more work to be spelled out in detail, but it suggests that RRR can explain not only moral requirements but applies to the deontic realm more generally.

\section{Concluding Remarks}

Deontic buck-passing is an attractive view to explain moral requirements, and the most convincing version of deontic buck-passing understands requirements in terms of both most reason to $\varphi$ and most reason to require to $\varphi$. Proponents of RRR must answer two open questions: they must explain why there can be only most reason to require $\mathrm{A}$ to $\varphi$ if $\mathrm{A}$ has most reason to $\varphi$, and they must give a convincing account of the role of agent-relative reasons. I have argued that both questions are best answered within a value-based theory of practical reasons.

This has an interesting upshot. It suggests that we cannot be buck-passers all the way down. Accepting deontic buck-passing requires giving up evaluative buck-passing. The result is a twolevel theory of moral explanation. On the first level, we explain practical reasons in terms of appropriate responses to valuable entities, and on the second level, we explain moral 
requirements in terms of reasons - reasons to act as well as reasons to require. ${ }^{24}$ It will require more work to spell out this view in detail, but I hope to have shown that RRR is a promising way to go.

joerg.loeschke@philos.uzh.ch

\section{References}

Bedke, Matt (2011): Passing the Deontic Buck. Oxford Studies in Metaethics 6, 128-153.

Broome, John (1999): Normative Requirements. Ratio XII, 398-419.

- (2013): Rationality Through Reasoning. Chichester: Wiley Blackwell.

- (2015): Reason Versus Ought. Philosophical Issues 25, 80-97.

Dancy, Jonathan (2000): Should We Pass the Buck? Royal Institute of Philosophy Supplement 47, 159-173.

- (2004): Ethics Without Principles. Oxford: Oxford University Press.

Darwall, Stephen (2010): But It Would Be Wrong. Social Philosophy and Policy 27, 135-157.

Gibbard, Alan (2010): Wise Choices, Apt Feelings. Cambridge: Cambridge University Press.

Dorsey, Dale (2013): The Supererogatory, and How to Accommodate It. Utilitas 25, 355-382.

Fogal, Daniel (2016): Reasons, Reason, and Context. In Errol Lord and Barry Maguire (eds.):

Weighing Reasons. Oxford: Oxford University Press: 74-103.

Hurka, Thomas (2001): Virtue, Vice, and Value. Oxford: Oxford University Press.

\footnotetext{
${ }^{24}$ For the idea of a two-level theory of moral explanation with a different focus see Maguire [2016].
} 
Keller, Simon (2013): Partiality. Princeton: Princeton University Press.

Lord, Errol (2016): Justifying Partiality. Ethical Theory and Moral Practice 19, 569-590.

Maguire, Barry (2016): The Value-Based Theory of Reasons. Ergo 3, 233-262.

McHugh, Conor/Way, Jonathan (2012): Fittingness First. Ethics 126, 575-606.

McElwee, Brian (2011): Impartial Reasons, Moral Demands. Ethical Theory and Moral Practice 14, 457-466.

Nagel, Thomas (1986): The View from Nowhere. New York: Oxford University Press.

Olson, Jonas (2013): Buck-Passing Accounts. In Hugh LaFollette (ed.): The International Encyclopedia of Ethics. Oxford: Wiley-Blackwell, 625-636.

Raz, Joseph (1999): Reason and the Will. In: Engaging Reason: On the Theory of Value and Action Oxford: Oxford University Press, 90-117.

Scanlon, Thomas (1998): What We Owe to Each Other. Cambridge: Belknap Press.

Schroeder, Mark (2007): Slaves of the Passions. Oxford: Oxford University Press.

Skorupski, John (2010): The Domain of Reasons. Oxford: Oxford University Press.

Snedegar, Justin (2016): Reasons, Oughts, and Requirements. Oxford Studies in Metaethics 11, $155-181$.

Suikkanen, Jussi (2009): Buck-passing accounts of value. Philosophy Compass 4, 768-779.

Väyrynen, Pekka (2006): Resisting the Buck-Passing Account of Value. Oxford Studies in Metaethics 1, 295-324.

Yetter Chappel, Richard (2012): Fittingness: The Sole Normative Primitive. The Philosophical Quarterly 62, 684-704. 
Wedgwood, Ralph (2013): The Weight of Moral Reasons. Oxford Studies in Normative Ethics $3,35-57$.

Whiting, Daniel (2017): Against Second-Order Reasons. Nous 51, 398-420.

Williams, Bernard (1995): Internal Reasons and the Obscurity of Blame. In: Making Sense of Humanity. Cambridge: Cambridge University Press, 35-45. 